\title{
Gender differences in the measurement of pharmacists' job satisfaction
}

\author{
Manuel J. Carvajal ${ }^{1 *}$ (D), loana Popovici ${ }^{1}$ and Patrick C. Hardigan ${ }^{2}$
}

\begin{abstract}
Background: Men and women choose different levels of commitment in their careers and at home. Compared to men, women value the significance of tasks performed and social relations more and earnings less. The objective of this study was to explore whether male and female pharmacists show the same levels of satisfaction overall and with key facets of their job, whether overall satisfaction is associated with satisfaction with 12 key facets of pharmacists' jobs, and whether this association is similar for men and women.

Methods: The study used self-reported survey data collected from a random sample of licensed pharmacists practicing throughout the United States. The sample consisted of 436 males and 300 females. Pearson correlation coefficients were calculated to assess the association between overall job satisfaction and its key components. The 13 job satisfaction indices and the Pearson correlation coefficient values were compared by gender.

Results: Women were consistently more satisfied than men. Variations in overall job satisfaction were at best accompanied by moderate variations in the 12 job satisfaction facets, raising concerns about the validity of configuring a composite index from multiple indices of satisfaction.

Conclusion: The results of this study can be used by healthcare managers and policymakers to facilitate communication, enhance teamwork, and promote a better allocation of scarce resources. Since men and women responded differently to various facets of their jobs, a constant set of rewards and stimulants may not be equally effective for both genders as employers transform the workplace to more adequately meet practitioners' needs and increase their productivity.
\end{abstract}

Keywords: Gender disparities, Job-related preferences, Job satisfaction, Pharmacist workforce

\section{Background}

The job paths that people take along their career trajectories depend on individual differences, available openings, and existing constraints [1]. When pharmacists assess their current jobs versus alternative employment opportunities, they examine options with multiple characteristics including salary and benefits, location, work conditions, and potential for advancement, among others. These characteristics appear in fixed bundles, and pharmacists seldom are able to choose only the ones they value and/or eschew those they do not like. For example, a job that pays well may demand unattractive work schedules, a promotion may entail moving to an

\footnotetext{
* Correspondence: cmanuel@nsu.nova.edu

1Department of Sociobehavioral and Administrative Pharmacy, College of Pharmacy, Nova Southeastern University, 3200 South University Drive, Fort Lauderdale, FL 33328-2018, United States of America

Full list of author information is available at the end of the article
}

undesirable location, or a position that carries more prestige may be accompanied by numerous stressful episodes. Choices invariably require a metric for weighing and trading off advantages and disadvantages.

The congruency between the kind of work that pharmacists do and the conditions under which they do it, on the one hand, and their idea of a "perfect job," on the other hand, measures the extent of their job satisfaction [2] and has received worldwide recognition as a proxy for professional utility [3-6]. It is a multidimensional concept that compares the reality of a work environment to workers' desires and expectations, allowing social and administrative pharmacists to analyze the well-being generated from experiences in a position and/or work setting.

The idea of a "perfect job" is influenced by perceptions, attitudes, and opinions developed from values and social

(C) The Author(s). 2018 Open Access This article is distributed under the terms of the Creative Commons Attribution 4.0 International License (http://creativecommons.org/licenses/by/4.0/), which permits unrestricted use, distribution, and 
cues that affect pharmacists of both genders differently, or are interpreted differently. Men and women tend to choose dissimilar levels of commitment in the career and home portions of their lives in response to their socially defined, differentiated involvement with childcare and household responsibilities $[7,8]$. They also assign unequal weights to identical job characteristics $[9,10]$; compared to men, women are likely to value the significance of tasks performed and social relations at work more and consider earnings as a less important aspect of their job. Thus, gender often mediates perceived levels of satisfaction [11].

Job satisfaction indices may be measured in two ways. The first, called a facet-free item, focuses on an aggregate satisfaction scale without reference to specific aspects imbedded into it; the second way, called a facet item, is derived as a composite measure from various indices of satisfaction with key aspects of a job [12]. Using an aggregate measure is easier and avoids methodological problems related to assigning weights to the various facets of one's job, accounting for different frames of reference, and ensuring that all relevant areas comprising job satisfaction are identified [13], but it has been shown to overestimate satisfaction and underestimate dissatisfaction [14]. Implicit in the use of the facet item is the expectation of a strong association between the overall index of job satisfaction and each of the indices of satisfaction with key facets of a job; otherwise, the validity of the instrument would be questionable.

\section{Objectives}

Within the context of the ideas expressed in the introduction, this paper sought to explore three questions: First, do male and female pharmacists show the same levels of satisfaction both overall and with key facets of their job? Second, is the level of overall satisfaction strongly associated with the level of satisfaction with key facets of pharmacists' jobs? And third, is the association similar for male and female pharmacists?

\section{Methods}

This study was based on self-reported survey data. Participants were asked to assess their overall job satisfaction as well as satisfaction with key facets of their job along 0-to-10 intensity scales, with 10 denoting the greatest intensity. This procedure posed the advantage of response homogeneity as practitioners expressed their perceptions regarding various facets of their job following a common measurement standard. It provided more room for discrimination in practitioners' responses than is normally provided by the Likert scale. Since there was no room for outliers, the mean was an adequate measure of central tendency. This scale has been used successfully to measure differentials in job-opinion variables $[15,16]$.
Besides overall satisfaction, 12 individual facets were included: adequacy of salary and benefits, workload, stress, advancement opportunities, job security, autonomy, fairness in the workplace, scheduling flexibility, job atmosphere, job importance to patients, supervisor's support, and relations with coworkers. Perceived workload and stress were anticipated to detract from job satisfaction, while the other facets were anticipated to add to it. Mean indices were calculated for each of these facets and their joint variation with the overall satisfaction index was estimated using Pearson correlation coefficients. These analyses were conducted by gender and for both genders combined. The disaggregation by gender took into consideration different values previously reported in the literature for male and female pharmacists $[8,17]$, a disaggregation not commonly found by any other independent variable.

\section{Variables}

Wages and salaries are the ultimate indicator of success for the American worker. A high income within the profession communicates to the world that a pharmacist is capable of coping with the pressures of the labor market and the many challenges raised by patients, employers, and peers interacting in complex ways. Thus, it is not surprising that overall job satisfaction has been linked to perceived adequacy of salary and benefits as well as intention to quit [18-20].

An excessive workload is a major source of dissatisfaction for pharmacists [21-24]; it is associated with more dispensing errors and reduced interaction with patients, which is viewed adversely by pharmacists [25]. Another source of dissatisfaction is stress [26, 27], which may lead to burnout [28, 29]; it arises when pharmacists experience unfavorable conditions over which they have no control such as role ambiguity and role conflict, unreasonable expectations from employers, and inadequate support in terms of physical or human resources [30-32].

Pharmacists' and other professionals' levels of job satisfaction increase with their perception of available advancement opportunities [33-35]; this is an important consideration because several studies suggest that pharmacy as a profession experiences shortcomings in satisfying the work ambitions of its practitioners [36]. Perceptions of job security also exert important effects on the pharmacist workforce through labor productivity, employment, and other outcomes and are one of the top motivating influences to enter the profession [37, 38]. Still another facet of job satisfaction is the ability to exercise one's judgment in conducting professional activities and controlling allocation of one's time; more discretion provides pharmacists with a sense of autonomy conducive to caring more about what they do, 
feeling better about it, and rendering better care to patients [20,39].

Fairness in the workplace, also known as organizational justice, is probably the most subjective concept analyzed here for it involves not only de facto inequalities, which may be explained by market differentials, but also interpretation and feelings by pharmacists; perceived disparities in how workers are treated account for a great deal of dissatisfaction [34, 40]. Scheduling flexibility is another factor appealing to pharmacists when they compare jobs insofar as it allows them to find a better balance between the personal- and work-related aspects of their lives and reduces stressors [41-43]; part-time employment, non-standard work, flexible hours, and specialized leave policies are some of the initiatives being implemented worldwide to accommodate non-work activities [44]. Also conducive to job satisfaction (or the lack thereof) is job atmosphere, alternatively known as organizational climate [20]; it refers to employees' perception of the typical practices and behaviors that prevail in the workplace, especially those that accord with expectations and consequently are rewarded.

The perceived importance of one's job to patients is another contributor to pharmacists' contentment [21, 45, 46]; interacting with patients and contributing to their wellbeing rank consistently high in the literature as intrinsic sources of satisfaction. Support from one's supervisor also fosters contentment by virtue of increasing confidence and relieving anxiety [4749]; according to Kahaleh and Gaither [50], this occurs when pharmacists acquire empowerment, which engenders greater organizational commitment. Good relations with coworkers is the last satisfaction-related facet analyzed here; not only do coworkers provide a dynamic and interactive background for self-expression, but they also form informal networks characterized by a horizontal flow of communication preferred by employees over channels of authority through which commands and information are transmitted downward and upward [51]. Several studies indicate that good relations with coworkers lead to job satisfaction by pharmacists $[5,26,41]$.

As a general rule, average index values under 3.00 were considered low, values ranging from 3.00 to 6.99 were considered moderate, and values 7.00 and above were considered high. Similarly, Pearson correlation coefficient (absolute) values under 0.30 were viewed as indicative of a weak link, values from 0.30 to 0.69 were viewed as moderate, and values of 0.70 or higher were viewed as indicative of a strong joint variation between the overall job satisfaction index and the 12 indices hypothesized to configure job satisfaction. The values of the empirical Pearson correlation coefficients were anticipated to be above 0.70 .

\section{Data}

The survey data were gathered from responses to a questionnaire sent to 2400 pharmacists practicing throughout the United States. These pharmacists were selected by Medical Marketing Services (MMS) using a simple random sampling scheme. MMS is a leading provider of lists of pharmacists and other healthcare professionals. Its data depository is drawn from practitioners registered with APhA, ASHP, AACP, and other organizations and includes pharmacists from all fields within the profession. Approximately $90 \%$ of the estimated 281560 pharmacists practicing in 2012 were included in the MMS data files [52].

A survey questionnaire, previously validated and exclusively designed for this and other workforce studies, was mailed by the authors in March 2012, with a reminder sent 2 weeks later. The sample size was chosen according to Cochran [53] formula developed for categorical and other outcomes, with a 5\% sampling error. The research effort was supported solely by internal university funds, and institutional review board approval was secured to conduct the probe.

\section{Statistical tests}

Significant differences between male and female pharmacists for the overall job satisfaction index and the 12 individual indices hypothesized to configure job satisfaction were established using the $t$ statistic for comparing the means of two distributions with unequal variances and unequal numbers of observations. This is a commonly used statistical test. Significant differences between genders in the Pearson correlation coefficient values for the 13 indices were established using the method developed by Fisher [54]. This procedure also was based on the $t$ distribution. Since the procedure is not commonly used, its formulation is presented below:

$$
t=\frac{r \prime_{m i}-r \prime_{w i}}{\sqrt{\frac{1}{n_{m}-3}+\frac{1}{n_{w}-3}}}
$$

where

$$
\begin{aligned}
& r \prime_{m i}=0.5 \log _{e}\left(\frac{1+r_{m i}}{1-r_{m i}}\right), \\
& r \prime_{w i}=0.5 \log _{e}\left(\frac{1+r_{w i}}{1-r_{w i}}\right),
\end{aligned}
$$

$r_{m i}$ was the male pharmacists' Pearson correlation coefficient for the $i$ th index;

$r_{w i}$ was the female pharmacists' Pearson correlation coefficient for the $i$ th index;

$n_{m}$ was the number of male pharmacists in the sample; 
$n_{w}$ was the number of female pharmacists in the sample; and

$i=1, \ldots, 13$ for the overall job satisfaction index and the 12 indices hypothesized to configure job satisfaction.

Three levels of significance (two-tail tests) were identified: $p \leq 0.01, p \leq 0.05$, and $p \leq 0.10$.

\section{Results}

Of the 2400 questionnaires mailed to potential participants, 139 packets were returned undelivered for various reasons. A total of 736 pharmacists participated in the study by providing answers to all relevant questions. The numbers of observations and the response rates compared favorably with those reported by similar undertakings [4, 22, 55-57]. Of these, 436 pharmacists (59.2\%) were men and 300 pharmacists $(40.8 \%)$ were women. Male pharmacists' median age was 57 years and female pharmacists' median age was 48 years. More men $(81.0 \%)$ than women $(72.9 \%)$ were married and men also had, on average, more years of professional experience than women (30.6 years and 22.5 years, respectively). Approximately two thirds of pharmacists in the sample worked in the retail sector (63.0\% for men and $63.4 \%$ for women).

\section{Indices}

The means and standard deviations of the overall job satisfaction index and the facet indices hypothesized to configure job satisfaction are presented in Table 1. The values of all 13 indices were in the moderate range. Perceived job importance to patients, amount of workload, and good relations with coworkers reported the top three index values. Availability of advancement opportunities showed by far the lowest level of satisfaction, followed by perceived support from one's supervisor and scheduling flexibility.

Male pharmacists' overall level of satisfaction was lower than the level of female pharmacists, and the difference was statistically significant. Higher levels for women also appeared for the facet indices, and all differences were significant except fairness in the workplace.

\section{Joint variation}

The estimated values of the Pearson correlation coefficients between the overall job satisfaction index and each of the 12 facet indices are presented in Table 2 . None of them exhibited a strong joint variation and all showed a positive sign. Fairness in the workplace and job atmosphere recorded the highest values, while stress, availability of advancement opportunities, and amount of workload had the lowest values. Four of the facet indices exhibited significant differences at various levels between male and female pharmacists in their correlation with the overall satisfaction index of the same gender:
Table 1 Means and standard deviations (in parentheses) of the overall job satisfaction index and indices hypothesized to configure job satisfaction

\begin{tabular}{|c|c|c|c|}
\hline \multirow[t]{2}{*}{ Variables } & \multicolumn{3}{|c|}{ Index values } \\
\hline & $\begin{array}{l}\text { Both } \\
\text { genders }\end{array}$ & $\begin{array}{l}\text { Male } \\
\text { pharmacists }\end{array}$ & $\begin{array}{l}\text { Female } \\
\text { pharmacists }\end{array}$ \\
\hline Number of observations & 736 & 436 & 300 \\
\hline Overall job satisfaction & $\begin{array}{l}6.03 \\
(3.01)\end{array}$ & $\begin{array}{l}5.71^{*} \\
(3.22)\end{array}$ & $\begin{array}{l}6.49 * \\
(2.60)\end{array}$ \\
\hline Adequacy of salaries and benefits & $\begin{array}{l}6.35 \\
(2.83)\end{array}$ & $\begin{array}{l}6.19^{\dagger} \\
(3.00)\end{array}$ & $\begin{array}{l}6.56^{\dagger} \\
(2.57)\end{array}$ \\
\hline Workload & $\begin{array}{l}6.81 \\
(2.54)\end{array}$ & $\begin{array}{l}6.56^{*} \\
(2.68)\end{array}$ & $\begin{array}{l}7.18^{*} \\
(2.28)\end{array}$ \\
\hline Stress & $\begin{array}{l}6.38 \\
(2.91)\end{array}$ & $\begin{array}{l}5.99^{*} \\
(3.08)\end{array}$ & $\begin{array}{l}6.95^{*} \\
(2.52)\end{array}$ \\
\hline Advancement opportunities & $\begin{array}{l}3.40 \\
(2.99)\end{array}$ & $\begin{array}{l}3.21^{\neq} \\
(2.92)\end{array}$ & $\begin{array}{l}3.69^{\ddagger} \\
(3.07)\end{array}$ \\
\hline Job security & $\begin{array}{l}6.00 \\
(3.02)\end{array}$ & $\begin{array}{l}5.75^{*} \\
(3.20)\end{array}$ & $\begin{array}{l}6.36^{*} \\
(2.71)\end{array}$ \\
\hline Autonomy & $\begin{array}{l}5.88 \\
(2.77)\end{array}$ & $\begin{array}{l}5.73^{\dagger} \\
(2.87)\end{array}$ & $\begin{array}{l}6.11^{\dagger} \\
(2.60)\end{array}$ \\
\hline Fairness in the workplace & $\begin{array}{l}6.02 \\
(2.94)\end{array}$ & $\begin{array}{l}5.92 \\
(3.08)\end{array}$ & $\begin{array}{l}6.17 \\
(2.72)\end{array}$ \\
\hline Scheduling flexibility & $\begin{array}{l}5.70 \\
(3.20)\end{array}$ & $\begin{array}{l}5.40^{*} \\
(3.23)\end{array}$ & $\begin{array}{l}6.14^{*} \\
(3.09)\end{array}$ \\
\hline Job atmosphere & $\begin{array}{l}6.17 \\
(2.80)\end{array}$ & $\begin{array}{l}6.02^{\dagger} \\
(2.90)\end{array}$ & $\begin{array}{l}6.40^{\dagger} \\
(2.64)\end{array}$ \\
\hline Job importance to patients & $\begin{array}{l}6.95 \\
(3.19)\end{array}$ & $\begin{array}{l}6.44^{*} \\
(3.53)\end{array}$ & $\begin{array}{l}7.68^{*} \\
(2.47)\end{array}$ \\
\hline Supervisor's support & $\begin{array}{l}5.49 \\
(3.28)\end{array}$ & $\begin{array}{l}5.16^{*} \\
(3.34)\end{array}$ & $\begin{array}{l}5.97^{*} \\
(3.13)\end{array}$ \\
\hline Relations with coworkers & $\begin{array}{l}6.60 \\
(2.76)\end{array}$ & $\begin{array}{l}6.34^{*} \\
(2.94)\end{array}$ & $\begin{array}{l}6.99^{*} \\
(2.45)\end{array}$ \\
\hline
\end{tabular}

*Statistically significant between genders $(p \leq 0.01)$

$\neq$ Statistically significant between genders $(p \leq 0.05)$

†Statistically significant between genders $(p \leq 0.10)$

the coefficients for stress and perceived job importance to patients were higher for male than female pharmacists, while the opposite was found for availability of advancement opportunities and perceived support from one's supervisor.

\section{Discussion}

The empirical evidence suggests that pharmacy as a profession experiences shortcomings in satisfying the work ambitions of its practitioners, as a generalized perception of limited opportunities for career advancement seems to be prevalent. Similar findings have been reported by earlier studies in the USA and the UK $[58,59]$.

The finding of moderate overall and facet index values of job satisfaction also accords with the results of previous studies [36]. So does the finding of a higher overall satisfaction index value for female 
Table 2 Pearson correlation coefficients of male and female pharmacists in the sample between the overall job satisfaction index and indices hypothesized to configure job satisfaction

\begin{tabular}{llll}
\hline Variables & \multicolumn{3}{l}{$\begin{array}{l}\text { Pearson correlation coefficients with } \\
\text { the overall satisfaction index }\end{array}$} \\
\cline { 2 - 4 } & $\begin{array}{l}\text { Both } \\
\text { genders }\end{array}$ & $\begin{array}{l}\text { Male } \\
\text { pharmacists }\end{array}$ & $\begin{array}{l}\text { Female } \\
\text { pharmacists }\end{array}$ \\
\hline Number of observations & 736 & 436 & 300 \\
Adequacy of salaries and benefits & 0.467 & 0.433 & 0.519 \\
Workload & 0.323 & 0.347 & 0.236 \\
Stress & 0.239 & $0.278^{\ddagger}$ & $0.099^{\ddagger}$ \\
Advancement opportunities & 0.241 & $0.187^{\dagger}$ & $0.319^{\dagger}$ \\
Job security & 0.504 & 0.486 & 0.524 \\
Autonomy & 0.505 & 0.486 & 0.537 \\
Fairness in the workplace & 0.615 & 0.598 & 0.652 \\
Scheduling flexibility & 0.465 & 0.461 & 0.453 \\
Job atmosphere & 0.584 & 0.559 & 0.631 \\
Job importance to patients & 0.410 & $0.457^{*}$ & $0.287^{*}$ \\
Supervisor's support & 0.516 & $0.466^{\ddagger}$ & $0.595^{\ddagger}$ \\
Relations with coworkers & 0.490 & 0.459 & 0.533 \\
\hline
\end{tabular}

*Statistically significant between genders $(p \leq 0.01)$

₹Statistically significant between genders $(p \leq 0.05)$

tStatistically significant between genders $(p \leq 0.10)$

than male pharmacists $[45,60]$. Particularly interesting was the gender differential in perceived adequacy of salaries and benefits despite the lower level of annual wages and salaries $(p \leq 0.01)$ reported by female pharmacists ( $\$ 105221)$ than by male pharmacists $(\$ 116912)$ in the same data set. This observed incongruity is known in the literature as the paradox of the contented female worker [33, 61, 62] and is explained in terms of women having lower market expectations, feeling less social pressure at work, and internalizing their feelings of professional disillusionment to a greater extent than do men.

Also interesting was the fact that women complained more than men about the amount of workload and stress; yet female pharmacists actually worked less ( $37.6 \mathrm{~h}$ per week) than their male counterparts ( $40.0 \mathrm{~h}$ per week), and the difference was statistically significant $(p \leq 0.01)$. Availability of advancement opportunities, job security, and autonomy have been found in other studies to concern men more than women $[31,38,63]$, but in this study, the opposite was the case. The relationship between the observed values of female and male pharmacists of the remaining facet indices-scheduling flexibility, job atmosphere, job importance to patients, support from one's supervisor, and good relations with coworkersconformed to expectations. These are considerations that traditionally affect women more than men; the greater index values obtained for female than male pharmacists reinforced the characterization of these variables as compensating differentials, that is, important work conditions for which female pharmacists showed more willingness than men to trade off earnings [7-10]. In other words, women practitioners seemed not only to place a greater emphasis on, but also be more satisfied by, social relations at work and the significance of tasks performed than men practitioners.

Contrary to expectations, both the perceived amount of workload and stress portrayed a positive joint variation with overall job satisfaction. This finding suggests that while within a specific job, an excessive workload and greater stress may detract from contentment, pharmacists generally accept that otherwise satisfying jobs require more work and stress than other jobs with fewer sources of contentment; as Gaither, Kahaleh, Doucette, Mott, Pederson, and Schommer [64] have pointed out, the practice of the profession can be both satisfying and highly stressful. In any event, the values of the coefficients were relatively low.

Perhaps the most important finding of this article was the absence of a strong joint variation between the overall job satisfaction index and the facet indices hypothesized to configure job satisfaction. Only fairness in the workplace and job atmosphere showed a correlation coefficient value higher than 0.60 , both for female pharmacists, while seven indices-adequacy of salary and benefits, amount of workload, stress, availability of advancement opportunities, scheduling flexibility, job importance to patients, and relations with coworkersshowed correlation coefficients under 0.50 . This seemed to question the validity of deriving a composite measure of satisfaction from various indices pertaining to key facets of a job. The empirical evidence clearly reveals that variation in the overall job satisfaction index proceeded independently of variation in nearly all individual facets. The validity of deriving a composite measure of job satisfaction was further challenged by the fact that four of the 12 facet indices exhibited significant differences between genders in their correlation coefficients with overall job satisfaction. The derivation of such a measure is likely to be flawed if differences between male and female pharmacists are not taken into account.

The findings reported here are subject to several limitations. The first limitation is that self-reported data were used, which by their very nature are open to validity and reliability criticism even though the questionnaire was tested prior to being mailed to participants. Job satisfaction is a highly subjective issue, and people's emotions and feelings may change frequently. The study rested on a cross-sectional survey; therefore, it was inadequate to measure whether the perception of overall job satisfaction and its various facets fluctuate over time, or the extent to which such fluctuations are affected by the growth of the pharmacist workforce or the rapidly changing healthcare reform situation. Future research ought to 
include longitudinal data in an attempt to understand the evolving roles of the facets of job satisfaction in determining the overall picture in different time periods.

The applicability of the findings also is limited by the environmental shifts that have occurred since 2012, when the data were collected. With a focus on reducing healthcare costs and improving clinical outcomes, recent years have witnessed the development of alternative payment and delivery models such as accountable care organizations and the emergence of pharmacogenomic testing. Consequently, the role of the pharmacist continues to expand and incorporate collaborative team-based care, medication therapy management and reconciliation, preventive care services, and patient education and behavioral counseling, all of which are likely to affect perceptions of job satisfaction. Other environmental shifts include the proliferation of pharmacy schools and graduates leading to surpluses in the pharmacist workforce and the growing shift toward mail-ordered distribution of prescription drugs.

Finally, another limitation is that no incentives such as monetary compensation or raffle prizes were used to motivate survey participation; they might have altered not only the number of respondents but also the nature of the responses. Potential biases arising from the omission of facets also need be recognized. Furthermore, there was no way to corroborate that the questionnaires were received and filled by the intended respondents, which was crucial to the issue of validity.

\section{Conclusion}

Despite its limitations, this study was successful in measuring and comparing male and female pharmacists' overall job satisfaction as well as satisfaction with key facets of their jobs. It has identified the facets in which pharmacists reported higher and lower levels of contentment with their work, and it has shown that women were consistently more satisfied than men, even though they earned lower wages and salaries and reported greater workload and more job-related stress. It also has shown that variations in overall job satisfaction were at best accompanied by moderate variations in all facets identified in this paper as concomitants, thus raising questions about the validity of configuring a composite index from multiple indices of satisfaction with the various facets of a job. The fact that male and female practitioners differed in their observed correlation coefficient values in some facets poses additional doubts about the validity of such a procedure.

Understanding the sources and extent of job satisfaction experienced by the pharmacist workforce is likely to guide employers to prepare and alter the workplace to more adequately meet practitioners' needs and increase their productivity. Men and women seemed to respond differently to the various facets, so a constant set of rewards and stimulants may not be equally effective for both genders. The empirical evidence reported here is expected to be used by healthcare managers and policymakers to facilitate communication, enhance teamwork, and promote a better allocation of scarce resources.

\section{Additional file}

Additional file 1: Survey questionnaire. (DOCX $18 \mathrm{~kb}$ )

\section{Abbreviations}

AACP: American Association of Colleges of Pharmacy; APhA: American Pharmacists Association; ASHP: American Society of Health-System Pharmacists; MMS: Medical Marketing Services

\section{Funding}

This research was supported solely by internal university funds. It did not receive any specific grant from funding agencies in the public, commercial, or not-for-profit sectors.

Availability of data and materials

All data generated or analyzed during this study are included in this published article and its Additional file 1.

\section{Authors' contributions}

All authors contributed equally to this study. All authors read and approved the final manuscript.

\section{Ethics approval and consent to participate}

Nova Southeastern University Institutional Review Board approval \# PHA053111 was secured to conduct the study. Informed consent occurred via cover letter of the survey.

\section{Consent for publication}

Study participants were informed in the cover letter that all of the information collected will be anonymous and results will be reported as group summaries, with no identifying information revealed.

\section{Competing interests}

The authors declare that they have no competing interests.

\section{Publisher's Note}

Springer Nature remains neutral with regard to jurisdictional claims in published maps and institutional affiliations.

\section{Author details}

${ }^{1}$ Department of Sociobehavioral and Administrative Pharmacy, College of Pharmacy, Nova Southeastern University, 3200 South University Drive, Fort Lauderdale, FL 33328-2018, United States of America. ${ }^{2}$ College of Medicine, Nova Southeastern University, 3200 South University Drive, Fort Lauderdale, FL 33328-2018, United States of America.

Received: 2 October 2017 Accepted: 5 July 2018

Published online: 31 July 2018

\section{References}

1. Biemann T, Zacher H, Feldman DC. Career patterns: a twenty-year panel study. J Vocat Behav. 2012;81:159-70.

2. Thorsteinson TJ. Job attitudes of part-time vs. full-time workers: a metaanalytic review. J Occup Organ Psychol. 2003;76:151-77.

3. Ahmad A, Khan MU, Elkalmi RM, Jamshed SQ, Nagappa AN, Patel I, Balkrishnan R. Job satisfaction among Indian pharmacists: an exploration of affecting variables and suggestions for improvement in pharmacist role. Indian J Pharm Educ. 2016;50:9-16. 
4. Al Khalidi D, Wazaify M. Assessment of pharmacists' job satisfaction and job related stress in Amman. Int J Clin Pharm. 2013;35:821-8.

5. Belay YB. Job satisfaction among community pharmacy professionals in Mekelle city, Northern Ethiopia. Adv Med Educ Pract. 2016;7:527-31.

6. Chua GN, Yee LJ, Sim BA, Tan KH, Sin NK, Hassali MA, Shafie AA, Ooi GS. Job satisfaction, organisation commitment and retention in the public workforce: a survey among pharmacists in Malaysia. Int J Pharm Pract. 2014;22:265-74.

7. Apps P, Rees R. Gender, time use, and public policy over the life cycle. Oxf Rev Econ Pol. 2005;21:439-61.

8. Carvajal MJ, Deziel L, Armayor GM. Labor supply functions of working male and female pharmacists: in search of the backward bend. Res Social Adm Pharm. 2012;8:552-66.

9. Bender KA, Donohue SM, Heywood JS. Job satisfaction and gender segregation. Oxf Econ Pap. 2005;57:479-96.

10. Kim S. Gender differences in the job satisfaction of public employees: a study of Seoul Metropolitan Government, Korea. Sex Roles. 2005;52:667-81.

11. Lau WM, Pang J, Chui W. Job satisfaction and the association with involvement in clinical activities among hospital pharmacists in Hong Kong. Int J Pharm Pract. 2011;19:253-63.

12. Awalom MT, Tesfa AF, Kidane ME, Ghebremedhin MR, Teklesenbet AH. Eritrean pharmacists' job satisfaction and their attitude to re-professionalize pharmacy in to pharmaceutical care. Int J Clin Pharm. 2015;37:335-41.

13. Lambert EG, Hogan NL, Barton SM. The impact of job satisfaction on turnover intent: a test of a structural measurement model using a national sample of workers. Soc Sci J. 2001;38:233-50.

14. Oshagbemi T. Overall job satisfaction: how good are single versus multipleitem measures? J Manag Psychol. 1999;14:388-403.

15. Carvajal MJ, Popovici I, Hardigan PC. Pharmacists' earnings determination: are part-time practitioners homogeneous in their response? J Pharm Health Serv Res. 2017:8:13-21.

16. Carvajal MJ, Armayor GM. The generational effect on pharmacists' labour supply. J Pharm Health Serv Res. 2015;6:11-8.

17. Carvajal MJ, Armayor GM, Deziel L. The gender earnings gap among pharmacists. Res Soc Adm Pharm. 2012:8:285-97.

18. Gaither CA, Nadkarni A, Mott DA, Schommer JC, Doucette WR, Kreling DH, Pedersen CA. Should I stay or should I go? The influence of individual and organizational factors on pharmacists' future work plans. J Am Pharm Assoc. 2007;47:165-73.

19. Gidman WK, Hassell K, Day J, Payne K. Does community pharmacy offer women family-friendly working conditions and equal opportunities? The accounts of female community pharmacists over the age of 30. Int J Pharm Pract. 2007:15:53-9.

20. Manan MM, Azmi Y, Lim Z, Neoh CF, Khan TM, Ming LC. Predictors of job satisfaction amongst pharmacists in Malaysian public hospitals and healthcare clinics. J Pharm Pract Res. 2015;45:404-11.

21. Liu CS, White L. Key determinants of hospital pharmacy staff's job satisfaction. Res Social Adm Pharm. 2011;7:51-63.

22. Murphy SM, Friesner DL, Scott DM. Do in-kind benefits influence pharmacists' labor supply decisions? J Reg Anal Policy. 2011;41:33-52.

23. Rothmann S, Malan M. Work-related well-being of South African hospital pharmacists. SA J Ind Psychol. 2011;37:1-11.

24. Willis $\mathrm{S}$, Elvey $\mathrm{R}$, Hassell $\mathrm{K}$. What is the evidence that workload is affecting hospital pharmacists' performance and patient safety? The University of Manchester. Manchester: Centre for Workforce Intelligence; 2011.

25. Mahrous S, Maziarz D. Community pharmacist shortage: fact or fiction? Pharm Times. 2008;74:58-9.

26. Hodgin R, Chandra A. Applying economic model 'efficiency wage' concept for pharmacists: can 'efficient' salaries reduce pharmacist turnover? J Health Manag. 2014;16:465-70.

27. Majd M, Hashemian F, Sisi FY, Jalal M, Majd Z. Quality of life and job satisfaction of dispensing pharmacists practicing in Tehran private-sector pharmacies. Iran J Pharm Res. 2012;11:1039-44.

28. Calgan Z, Aslan D, Yegenoglu S. Community pharmacists' burnout levels and related factors: an example from Turkey. Int J Clin Pharm. 2011;33:92-100

29. Eslami A, Kouti L, Javadi M-R, Assarian M, Eslami K. An investigation of job stress and job burnout in Iranian clinical pharmacist. J Pharm Care. 2015;3:21-5.

30. Hermansyah A, Sukorini Al, Setiawan CD, Priyandani Y. The conflicts between professional and nonprofessional work of community pharmacists in Indonesia. Pharm Pract (Granada). 2012;10:33-9.
31. Jacobs S, Hassell K, Ashcroft D, Johnson S, O'Connor E. Workplace stress in community pharmacies in England: associations with individual, organizational and job characteristics. J Health Serv Res Policy. 2014;19:27-33.

32. Lapane $\mathrm{K}$, Hughes $\mathrm{C}$. Job satisfaction and stress among pharmacists in the long-term care sector. Consult Pharm. 2006;21:287-92.

33. Bender KA, Heywood JS. Job satisfaction of the highly educated: the role of gender, academic tenure, and earnings. Scott J Polit Econ. 2006;53:253-79.

34. Parvin MM, Kabir MN. Factors affecting employee job satisfaction of pharmaceutical sector. Aust J Bus Manag Res. 2011;1:113-23.

35. Ubaka CM, Ochie UM, Adibe MO. Student pharmacists' career choices: a survey of three Nigerian schools of pharmacy. Pharm Pract (Granada). 2013;11:149-55.

36. Carvajal MJ, Armayor GM, Hardigan PC. Socioeconomic profile of pharmacists in South Florida: who they are, what they do, how much they like it. Fort Lauderdale: Nova Southeastern University College of Pharmacy; 2010.

37. Flying High: Are rising wages and generous benefits enough to attract pharmacists and keep them from roaming? Drug Topics; 2005.[http://www. drugtopics.com/pharmacy-news/flying-high].

38. Foroughi Moghadam MJ, Peiravian F, Naderi A, Rajabzadeh A, Rasekh HR. An analysis of job satisfaction among Iranian pharmacists through various job characteristics. Iran J Pharm Res. 2014;13:1087-96.

39. Cavaco AM, Krookas AA. Community pharmacies automation: any impact on counselling duration and job satisfaction? Int J Clin Pharm. 2014;36:325-35.

40. Phua GSY, Teoh CJ, Khong LB, Baba B, Lim CW, Koh WL, Rhazi NAM, Ayob NC. The satisfaction and perception of intern pharmacists towards their training in government hospitals in the northern region of Malaysia. Pharm Educ. 2017;17:15-23.

41. Hawthorne N, Anderson C. The global pharmacy workforce: a systematic review of the literature. Hum Resour Health. 2009:7:48.

42. Jepsen DM, O'Neill MS. Australian hospital pharmacists reflect on career success. J Pharm Pract Res. 2013:43:29-31.

43. Seston E, Hassell K. British pharmacists' work-life balance-is it a problem? Int J Pharm Pract. 2014:22:135-45.

44. Omar MK. Work status congruence, work-related attitudes, and satisfaction towards work-life balance. Int Rev Bus Res Papers. 2010;6:145-56.

45. Seston E, Hassell K, Ferguson J, Hann M. Exploring the relationship between pharmacists' job satisfaction, intention to quit the profession, and actual quitting. Res Social Adm Pharm. 2009;5:121-32.

46. Shann P, Hassell K. An exploration of the diversity and complexity of the pharmacy locum workforce. Manchester: Royal Pharmaceutical Society of Great Britain; 2004.

47. Bagheri S, Kousha A, Janati A, Asghari-Jafarabadi M. Factors influencing the job satisfaction of health system employees in Tabriz, Iran. Health Promot Perspect. 2012;2:190-6.

48. Ferguson J, Ashcroft D, Hassell K. Qualitative insights into job satisfaction and dissatisfaction with management among community and hospital pharmacists. Res Social Adm Pharm. 2011;7:306-16.

49. Urbonas $G$, Kubiliene $L$, Kubilius $R$, Urbonienè A. Assessing the effects of pharmacists' perceived organizational support, organizational commitment and turnover intention on provision of medication information at community pharmacies in Lithuania: a structural equation modeling approach. BMC Health Serv Res. 2015;15:82.

50. Kahaleh A, Gaither C. The effects of work setting on pharmacists' empowerment and organizational behaviors. Res Social Adm Pharm. 2007:3:199-222.

51. Miller GJ, Yeager SJ, Hildreth WB, Rabin J. How financial managers deal with ethical stress. Public Adm Rev. 2005;65:301-12.

52. Occupational Employment and Wages: Pharmacists 2014: 29-1051. [https:// www.bls.gov/oes/2014/may/oes291051.htm].

53. Cochran WG. Sampling techniques. 2nd ed. New York: John Wiley and Sons Inc.; 1963.

54. Fisher RA. On the probable error of a coefficient of correlation deduced from a small sample. Metro. 1921;1:3-32.

55. Lin BY-J, Yeh $Y-C$, Lin W-H. The influence of job characteristics on job outcomes of pharmacists in hospital, clinic, and community pharmacies. J Med Syst. 2007;31:224-9.

56. Polgreen LA, Mott DA, Doucette WR. An examination of pharmacists' labor supply and wages. Res Social Adm Pharm. 2011;7:406-14.

57. Quiñones AC, Pullin RF. Reexamining shift work pharmacists in Illinois. Res Social Adm Pharm. 2011:7:444-50.

58. Carvajal MJ, Hardigan P. Phamacists' inter-gender differences in behavior and opinions: is work input an important mediator? Internet J Allied Health Sci Pract. 2008;6:1-22. 
59. Tanner J, Cockerill R, Barnsley J, Williams AP. Gender and income in pharmacy: human capital and gender stratification theories revisited. Br J Sociol. 1999;50:97-117.

60. Hassell K, Seston E, Shann P. Measuring job satisfaction of UK pharmacists: a pilot study. Int J Pharm Pract. 2007;15:259-64.

61. Bilimoria D, Perry SR, Liang X, Stoller EP, Higgins P, Taylor C. How do female and male faculty members construct job satisfaction? The roles of perceived institutional leadership and mentoring and their mediating processes. J Technol Transf. 2006;31:355-65.

62. Kaiser LC. Gender-job satisfaction differences across Europe: an indicator for labour market modernization. Int J Manpow. 2007;28:75-94.

63. Young S, LeMessurier J, Mathews M. The feminization of the Canadian pharmacy workforce: a gender analysis of graduates from a Canadian school of pharmacy. Can Pharm J. 2012;145:186-90.

64. Gaither CA, Kahaleh AA, Doucette WR, Mott DA, Pederson CA, Schommer JC. A modified model of pharmacists' job stress: the role of organizational, extra-role, and individual factors on work-related outcomes. Res Social Adm Pharm. 2008:4:231-43.

Ready to submit your research? Choose BMC and benefit from:

- fast, convenient online submission

- thorough peer review by experienced researchers in your field

- rapid publication on acceptance

- support for research data, including large and complex data types

- gold Open Access which fosters wider collaboration and increased citations

- maximum visibility for your research: over $100 \mathrm{M}$ website views per year

At $\mathrm{BMC}$, research is always in progress.

Learn more biomedcentral.com/submissions 